\title{
La revuelta napolitana de mediados del siglo XVII y don Juan José de Austria
}

\author{
Josefina Castilla Soto*
}

La década de los cuarenta supone una fecha clave en la historia del controvertido siglo XVII. La crisis de la Monarquía hispánica se traducía en múltiples grietas que parecian querer destruir definitivamente la infraestructura de la España de los Austrias. Los levantamientos se sucedian en Cataluña y Portugal y, aunque con menor entidad, se producian igualmente movimientos en otras zonas peninsulares, concretamente, en Andalucía y el País Vasco. La chispa prendió tambien en Nápoles, mientras en Flandes la beligerancia era casi continua.

Estas revueltas, ya graves en sí mismas y en sus motivaciones, se veian agravadas por la presencia de las potencias extranjeras embarcadas en su deseo de conseguir la reducción del poderío territorial hispano en beneficio propio.

En casi todos estos levantamientos tuvo oportunidad de intervenir don Juan José de Austria, ese personaje conflictivo y contradictorio al que, sin duda, debemos reconocer una especie de "mesianismo" que le llevó a acaparar las esperanzas de todo un pueblo a lo largo de varias décadas.

En 1642, con el reconocimiento de don Juan José como hijo natural de Felipe IV, tuvo lugar el comienzo de su vida pública, mientras su for-

* Profesora de Historia Moderna. UNED. 
mación militar se iba gestando al compás de su intervención en los acontecimientos bélicos que vivía la Monarquía de Felipe IV. De este modo, don Juan José se apresuró a participar en el sofocamiento de la revuelta napolitana.

Esta revuelta, que tuvo lugar en Nápoles a mediados del siglo XVII, se habia ido gestando desde finales del siglo XVI. En la primera mitad del siglo XVII había ya una clara diferenciación entre la Italia meridional y la Europa moderna. La decadencia de aquélla se ha venido relacionando, por parte de los historiadores, con la llamada "crisis general" del siglo XVII. Sin embargo, esta crisis, tuvo en Nápoles sus particulares connotaciones.

Allí, las estructuras feudales habían sobrevivido, de modo que cualquier iniciativa que había intentado actuar independientemente de ellas, había sido abortada. Además, los derechos típicamente señoriales, se vieron fortalecidos por la enorme disgregación social existente, lo que facilitó, de hecho la aparición de diversos partidos al frente de los tumultos ${ }^{\text {. }}$.

Este proceso involutivo que vivía la Italia meridional, está íntimamente conectado con la política allí practicada, especialmente en el período comprendido entre 1636 y 1647. Así, el incremento de la deuda pública, la intensificación de las presiones fiscales y la intervención de Nápoles en las empresas españolas ${ }^{2}$, se agravaba con la injerencia de los señores feudales en la administración pública.

Ya en las dos últimas décadas del siglo XVI surgió una corriente de oposición popular frente a la alianza Corona-Nobleza que se tradujo en la revuelta de 1585 , cuya causa inmediata fue la decisión de los Electos ${ }^{3}$ de aumentar el precio del pan en la capital. Mientras tanto, la Administración había autorizado, poco tiempo antes, la exportación de más de 400.000 túmulos de trigo a España.

1 B. N., Mns 2378, fols 119 y 120.

2 Nápoles, en este sentido, era un fiel reflejo de lo que ocurría en Castilla, en donde la presión fiscal y la deuda pública eran importantes problemas planteados. Concretamente, en 1647 se produjo una bancarrota que eliminó a la mayor parte de los banqueros reales. V. Dominguez Ortiz: Política y Hacienda de Felipe IV, Madrid 1960.

${ }^{3}$ El Consejo de los Electos era, junto con el Parlamento, el máximo órgano de gobierno. Era de constitución nobiliaria, a excepción de un representante del pueblo que fue incluido ya en tiempos de Carlos VIII. 
A las protestas del pueblo por el hambre, cabe añadir su admiración hacia el movimiento revolucionario flamenco, primera fractura, dentro de las posesiones españolas ${ }^{4}$.

Tras la revuelta de 1585 , se alivió ligeramente la carestía de los alimentos napolitanos pero, poco después, el precio del pan siguió subiendo. "En 1591 se produjeron conatos de motín en la Plaza de la Selleria ${ }^{5}$."

Las consignas revolucionarias, reflejadas en carteles y pasquines, tuvieron escaso eco popular y degeneraron en el bandidaje cuyo blanco fundamental eran los ricos. Tanto laicos como eclesiásticos, fueron víctimas de la extorsión.

Las "bandas" de "bandoleros" del Abruzo se reagruparon, constituyendo una organización única, bajo el mando de Marco Sciarra. En las ciudades, la actividad de Sciarra empezó a interpretarse como un movimiento de rebeldía frente a España; de ahi las simpatías que despertaba en diversos sectores napolitanos que anteriormente se habían mostrado reacios ante las acciones de otros bandoleros.

Debido al cariz político de esta banda de guerrilleros, ef gobierno tomó una serie de medidas encaminadas a romper el lazo existente entre los campesinos y los bandoleros: se destruyeron aldeas y se crearon milicias auxiliares en los municipios. Por su parte, la Iglesia, participó activamente en la represión del bandidaje. Incluso, se llegó a proponer que fuera un obispo el encargado de imponer la ley en el Abruzo.

Lo cierto, es que la revuelta napolitana de fines del siglo xvı y sus aspiraciones de independencia frente a España, no llegaron a triunfar debido a la disgregación social existente en el Reino y a la falta de un programa político-social coherente que garantizara una movilización unitaria de fuerzas.

4 Precisamente en Flandes «a lo largo de las décadas del sesenta y del setenta, hasta que la situación... se tornó absolutamente irreversible para España en 1579-81 con la Unión de Utrecht y la Declaración de soberania de La Haya, las medidas de Felipe (II) abarcaron un amplio y vacilante abanico".

J. AlCALA-Zamora y QUeIPO de Llano: «España y Flandes en el siglo de los Felipes", Historia 16, año $\mathrm{V}, n^{\circ} 45$, Madrid enero 1980, p. 49.

5 R. VILLARI: La revuelta antiespañola en Nápoles. Los Orígenes (1585-1647), Madrid, Alianza Universidad, 1979, p. 60. 
Ya en el primer tercio del siglo XVII, la deuda pública napolitana había alcanzado unas cifras insuperables. Este vacio en las arcas del Estado, trató de subsanarse por diferentes vías: venta de cargos, venta de tierras de realengo, aplicación de impuestos extraordinarios, etc... Sin embargo, estas medidas, eran insuficientes para contrarrestar la continua petición de ayuda por parte de la península. No en vano era «Nápoles, la metrópoli del Mediterráneo occidental, barbacana frente al turco y cabeza, con Castilla, de los recursos demográficos y económicos en que se basaba el poderío europeo del Rey de España ${ }^{6} . "$

Precisamente, las levas de soldados en Nápoles, solicitadas por la Monarquía hispana, provocaban auténticos tumultos, de ahí que se recurriera, con frecuencia, al uso de la fuerza.

En el primer tercio del siglo XVII se inició también una corriente de oposición al Gobierno entre las altas esferas nobiliarias, contrarias a la política financiera que se estaba llevando a cabo. Este movimiento, con carácter cerrado y corporativista, rechazaba cualquier acuerdo con otras fuerzas sociales y tuvo como consecuencia fundamental, la suspensión del parlamento, que no volvió a reunirse después de 1642.

Verdaderamente, resultaba del todo imposible una alianza de fuerzas entre aristocracia y clases populares, dado el círculo vicioso que se habia ido tejiendo entre: Corona (demandando continuamente ayudas de los grupos financieros), Nobleza (presionando al pueblo para obtener recursos con que responder a las demandas de la Corona sin menoscabo de su propio status y tren de vida) y clases populares (las más oprimidas, en definitiva) ${ }^{7}$.

En 1647 , en medio de un ambiente de epidemias, hambre y sequia, el Virrey, Duque de Arcos, gravó la fruta, alimento y principal comercio de la población napolitana. La reacción del pueblo no se hizo esperar, y en julio de 1647, una serie de sublevaciones populares, encabezadas por Tomás Aniello o Massaniello, exigieron, frente al palacio del Virrey, la

6 J. Alcala-Zamora y Queipo de Llano: “La Política exterior" (s. Xvili), Historia 16, año IV, Extra XII, Madrid diciembre 1979, p. 64.

2 «El aumento de la presión económica y política ejercida por la nobleza en las provincias y el incremento de la renta feudal - dos de las condiciones esenciales para la acumulación de los capitales suministrados al gobierno por los grupos financieros en vísperas de la revolución-, afectaban de forma inmediata y directa al conjunto de la vida administrativa política y económica” (R. VILLARI, op. cit. p. 164). 
supresión de las gabelas, al tiempo que dirigian ataques contra los nobles.

Los gritos de combate, en estos primeros momentos, mostraban que nada iba contra España pues eran los de ¡Viva la Virgen del Carmen!, ¡Viva el Rey!, ¡Abajo los malos gobiernos!

Surgieron así dos focos insurrectos de orígenes politico-sociales bien diferentes: la conjura nobiliaria, por un lado, y la insurrección popular, por otro. Ambas discurrieron de forma paralela sin llegar jamás a unificarse para alivio del Virrey.

Massaniello fue asesinado por el propio pueblo napolitano. Tras su muerte, la rebelión adoptó un carácter separatista. En apariencia, el nuevo caudillo era el Príncipe de Massano, quien realmente, intentaba la reconciliación entre el pueblo y el Duque de Arcos. Pero, quien verdaderamente manejaba la rebelión era Francia, cuyos bajeles y galeones se acercaban a Nápoles. Asimismo, después de varios meses de apresto y viaje, se aproximaba la Armada española.

Efectivamente, en la primavera de 1647 tuvo lugar la preparación de la Armada en Cádiz. «El Conde de Castrillo, del Consejo de Estado de su Magestad Presidente de su Consejo de Indias... acudió en persona por su Real orden al despacho de la Armada" ${ }^{8}$. Esta constaba de seis galeras, treinta y un bajeles de guerra y ocho de fuego. En ellos se embarcaron tres mil quinientos treinta y un hombres de guerra y tres mil cuatrocientos veintisiete de mar. A este contingente, debian unirsele las galeras de las escuadras de Nápoles, Sicilia y Génova.

Una Instrucción Real de 17 de abril, mandaba salir a don Juan José cuanto antes de los puertos andaluces, al frente de la Armada. Simultáneamente llegaban noticias de la preparación de la Armada francesa en Marsella y Tolón.

Don Juan José se embarcó el 5 de mayo (1647), partiendo el día 7 en que el tiempo se presentó más favorable. LLegaron, entretanto, despachos del Rey con noticias sobre la llegada a Cataluña de embarcaciones francesas con intención de atacar Tarragona o Tortosa. Por ello, don

B.N., Mns. 2378, fol. 49. 
Juan José se dirigió rápidamente a Tarragona, pasando por Peñíscola donde supo que el Príncipe de Condé «(informado, sin duda, de la calidad y resolución conque venia la armada de España aestorvarle sus intentos de la marina) havia mudado su primera disposicion con ponerse sobre Lérida, y que las galeras y navios, que habian porteado gente y artillería dos vezes a Barcelona havian buelto a Francia desde los siete de mayo" ${ }^{9}$.

Esta noticia le fue confirmada a don Juan a su llegada a Tarragona. Sin embargo, parte de los efectivos de la Armada, desembarcaron para garantizar la seguridad de Tarragona y Tortosa.

Gracias a la resistencia del Gobernador de Lérida, don Gregorio de Brito y a los padecimientos de los agresores ante la dilación de la empresa, los desembarcados volvieron de nuevo a ponerse en camino hacia Nápoles, con órdenes expresas de enfrentarse con la Armada francesa si ésta se encontrada en su camino.

La Armada se dirigió a Cerdeña. De allí llegó a Nápoles la noticia de la próxima arrivada de la Armada española a la ciudad y las manifestaciones, al respecto, no se hicieron esperar. Eran continuos los corrillos de la plebe en todas las plazas y especialmente en los muelles. Los más pertinaces eran partidarios de mantener a toda costa sus razones, mientras otros, especialmente las clases medias, proponian luchar por el mantenimiento de los puntos más esenciales, como eran, la abolición de las gabelas, la igualdad de votos con la nobleza y el perdón general.

Sin duda, lo que más influyó en las clases medias napolitanas, fue el comportamiento de Sicilia. La isla, por otro lado, "granero" de España, habia sido gravada bajo Carlos I, Felipe II y Felipe III, con impuestos muy ligeros, siendo respetados sus privilegios. Bajo Felipe IV y a tenor de las necesidades bélicas, se dispuso que los sicilianos debian colaborar también en llevar el peso de las cargas. Por ello, también en Sicilia se fijaron tasas sobre los artículos de primera necesidad (aceite, harina, carne, vino) pero que sólo recayeron en pobres y forasteros, mientras los nobles y clérigos mantenian sus privilegios de exención.

Asi pues, las características constitucionales de la isla, por un lado, y los desórdenes de la Administración, por otro, fueron el detonante de

9 Ibidem, fol. 53 . 
la revuelta en Sicilia. Sin embargo, los sicilianos, tras haber exigido el cumplimiento de 49 capítulos de contenido semejante a los de Nápoles, finalmente se contentaron con la abolición de las gabelas sobre los productos comestibles y el perdón, contagiando, sin duda, su moderación, a las clases medias napolitanas.

En este ambiente revolucionario, tuvo lugar la llegada al $1 .^{\circ}$ de octubre de 1647, de la Armada Real con don Juan José de Austria al frente. El Virrey, Duque de Arcos, informó al de Austria de cuanto estaba aconteciendo en Nápoles. En la ciudad habian surgido tantos partidos como cabecillas principales tenía la insurrección. Cada uno de ellos utilizaba toda clase de artificios para engrosar sus filas. Entre todos destacaba, sin duda, Genaro Annese, armero de oficio, el cual, utilizaba su tienda para propagar panfletos y avisos, al tiempo que planeaba un especial gobierno democrático para su patria.

Ante la noticia de la llegada de don Juan, proliferaron los discursos en pro y en contra de los españoles. Para unos, significaba una opresión, una tiranía, la dependencia de España.

“Es sin duda que el Príncipe viene con el mando de aquélla armada merece por quien es que se considere, mas quisiera, que también sus fines nos la hicieran considerable y que por los mismos midieramos nuestras atenciones. El venirnos a buscar dexando a la armada francesa y a los presidios de Puerto Longon y Piombin a sus espaldas, harta señal es que nostiene por mas enemigos de su padre, bien de los de confirmar nuestro alivio assi señores no haya sido acordarnos con magnanimidad memorable en los siglos de lo que pagamos al Rey de mas de lo que le desviamos por nuestros fueros y de lo que devemos a la patrias ${ }^{10}$.

Sin embargo, para otros, era crucial tratar de desplazar del escenario napolitano una guerra civil que a nadie iba a beneficiar.

Nada más llegar a Nápoles, don Juan José redactó un informe dirigido al Rey acerca de la situación encontrada allí para justificar su decisión de apaciguar primero la ciudad, en lugar de reducir Puerto Longón y Piombino, que era la orden prioritaria que traía del Rey.

\footnotetext{
${ }^{10}$ Ibidem, fol. 121. Discurso de un letrado, amigo de Jenaro Annese.
} 
En los dias sucesivos, se recrudecieron los combates ya que el Virrey, Duque de Arcos, se mostró partidario de utilizar la fuerza para reducir a los sediciosos.

"Todo daba a entender que, yendo a una don Juan de Austria y el severo e irascible Duque de Arcos, acabarían por ahogar aquélla rebelión en un mar de fuego y de sangre. Pero no fue así" ".

Efectivamente, aunque las órdenes de don Juan José eran las de ajustarse en todo al Virrey, sin embargo, bien por ingenio, bien por deseos de acabar pronto con las discordias, o bien, por su ambición de gloria, lo cierto es que don Juan se avino a negociar a espaldas del Virrey. El 12 de octubre de 1647, don Juan llamó en secreto a los Ministros del gobierno para consultarles sobre la conveniencia de relevar al Duque de Arcos del mando, como vía más segura para reducir los ánimos, puesto que el pueblo le odiaba.

Enterado de éstas maquinaciones, el Virrey trató de negociar con los amotinados, por su cuenta, mediante el cardenal Filomarino, pero éste rechazó el papel de mediador. En enero de 1648, el Duque de Arcos dejó el gobierno, siendo asumido éste por don Juan.

Desde España, llegó una cédula real confiriendo el Virreinato de Nápoles al Conde de Oñate, a la sazón, Embajador ante la Santa Sede, circunstancia que aprovechó don Juan José para escribirle suplicándole obtuviera del Papa, el rápido envío de un legado para que mediara en la paz. Pero el Papa, que había detectado la presencia francesa en Nápoles (Duque de Guisa), se negó a ello.

En marzo de 1648, el Conde de Oñate pasó a Nápoles ${ }^{12}$. Entretanto, muchos napolitanos empezaron a declararse contra el Rey de España, aclamando a don Enrique de Lorena, Duque de Guisa.

"A. Risco: Don Juan de Austria, hijo de Felipe IV. Juan de la Tierra. (Narración histporica), Madrid, Razón y Fe, 1918, p. 40.

${ }_{12}$ "El señor don Juan, que como se ha dicho se habia encargado de aquel govierno, desde que partio el Duque de Arcos, mando dar luego la possession del al Conde, que procuro continuar y estrechar las platicas que con mucha prudencia avia introducido Su Alteza con las cabeças del pueblo inobediente». (B.N., Mns. 2379, fol. 93). 
Hacía tiempo que Francia preparaba su intervención en los sucesos de Nápoles. En 1646 había tenido lugar una expedición francesa a los Presidios de Toscana para: a) estorbar las comunicaciones entre España e Italia y entre los propios territorios españoles de Italia, b) presionar políticamente a la Santa Sede para impedir las iniciativas favorables a España ${ }^{13}$ y c) imponer una política de neutralidad en Toscana. Incluso, en los primeros meses de 1646, Mazarino había llegado a firmar un tratado con el Príncipe Tomás de Saboya, estipulando que Francia dispensaría a éste ayuda y protección a cambio de la cesión de Gaeta y de un Puerto en el Adriático, en el caso de que los franceses consiguieran la Corona de Nápoles como consecuencia de una insurrección.

Sin embargo, y a pesar del empeño francés, el Conde de Oñate apresó al Duque de Guisa enviándole preso a Madrid. Rápidamente emprendió una ofensiva con avanzadillas que fueron tomando posiciones. Al propio tiempo, el pueblo empezó a colaborar y a vitorear al Rey. Así Nápoles y otras ciudades a imitación suya, se fueron reduciendo a la obediencia del Rey hispano. El Conde de Oñate indultó a todos los presos salvo a los que fueran franceses.

Con fecha 6 de abril de 1648, escribió don Juan José una carta a don Luis de Haro, comunicándole la total reducción de Nápoles en el día de la fecha, sin daños considerables para las partes. Si bien indica que:

... «bien reconozco que Su Majestad ha quedado sin rentas en este Reyno por la exençion de gabelas, pero tambien diré a V.E. que como el interes prinçipal esydebe ser siempre la seguridad del Reyno nome duelen ami tanto las demas conveniencias" ${ }^{14}$.

Fue importante en la reducción de Nápoles, la estrategia utilizada por los mandos españoles cuyo máximo empeño había sido sembrar la discordia entre los que gobernaban para acceder con facilidad al gobierno, granjeándose al mismo tiempo el favor de los civiles para que facilitaran la empresa.

${ }^{13}$ Esta política de presión a la Santa Sede, daría posteriormente sus frutos. En plena revuelta napolitana, el Papa se negó a enviar a don Juan un legado para que mediara en la paz, el detectar alli, la presencia francesa.

${ }^{14}$ B.N., Mns. 2379, fol. 121. 
El pueblo acabó colaborando por cansancio y, al mismo tiempo, por temor a las represalias de los españoles. Por su parte, la nobleza, se mantuvo siempre solidaria con la Monarquía hispana dado que ésta garantizaba plenamente sus privilegios.

Una vez aplacados los ánimos, don Juan José concedió unas gracias al pueblo de Nápoles con el fin de liberarles de las excesivas imposiciones con que se hallaba cargado ${ }^{15}$. Estas gracias se centraban fundamentalmente en la supresión de las gabelas que al gravar artículos de primera necesidad habían motivado el levantamiento del pueblo.

Entretanto, las noticias sobre la reducción de Nápoles llegaron a Madrid. Efectivamente, el 28 de abril de 1648, don Fernando Carrillo, Gentilhombre de la Cámare de S.A, aparecio en la puerta de Nuestra Señora de Atocha, con la noticia del aplacamiento de Nápoles. El Rey, Felipe IV, recibió la noticia en Aranjuez. De regreso a Madrid, el 2 de mayo de 1648, se manifestó públicamente en las calles de Madrid, acompañado de la más rancia nobleza, siendo aclamado por el pueblo.

Especial relevancia tuvieron las celebraciones que llevó a cabo el Consejo de Italia. El lugar elegido para dicho acontecimiento fue el Convento de los Angeles, de Monjas de la Seráfica Religión del Glorioso San Francisco, en donde tuvo lugar la instalación del Santísimo Sacramento, a lo largo de tres días. Las celebraciones religiosas se vieron acompañadas por manifestaciones musicales y fuegos de artificio y culminaron, el último día, con una solemne procesión.

Don Juan José fue nombrado Virrey y Capitán General de Sicilia por lo que permaneció en Italia, además, con una orden real prioritaria, la recuperación de las plazas de Puerto Longón y Piombino. Era fundamental aprovechar la coyuntura puesto que las plazas se encontraban mal guarnecidas debido a que Francia estaba viviendo las «revoluciones de Paris" y todo cuanto la Fronda trajo consigo.

El Conde de Oñate recibió las oportunas órdenes para preparar todo aquello que considerara conveniente, debía salir de Nápoles para intervenir en la empresa, en su calidad de Virrey y Capitán General de

${ }^{15} \mathrm{Ibidem}$, fols. 109 a 112 . Se trata de once capitulos en donde se recogen las gracias, privilegios e inmunidades concedidas al pueblo napolitano el 11 de abril de 1648 . 
Nápoles ${ }^{16}$. El Marqués de Caracena, por su parte, enviaría auxilios desde Milán. Mientras, don Juan, se ocuparía del apresto de la Armada:

«... vais aprestando la Armada con inteligencia de que no haviendo de salir este año la de Francia a navegar asi por las turbaçiones como por haver pasado la mayor parte della a Poniente, no sera necesario esperar todo el apresto de la nuestra" ${ }^{17}$.

Desde Madrid empezaron a divulgarse falsos rumores para hacer creer que la Armada que se preparaba estaba destinada a intervenir en Cataluña ${ }^{18}$. Don Juan, naturalmente, hizo suya dicha estrategia para lograr los efectos deseados y despistar, en lo posible, a los franceses en ambos frentes (Cataluña y los Presidios).

Las fuerzas españolas, además, poseían cumplida información sobre la situación en hombres y pertrechos de Puerto Longón y Piombino ${ }^{19}$. Una soldadesca impagada desde hacia meses, hambre, enfermedades y una artillería, en su mayor parte de hierro, esperaban a los españoles.

A pesar de todas las previsiones, preparadas en la primavera de 1649, llegaron noticias de Madrid, con la orden de posponer la empresa ya que el Conde de Oñate había tenido que enviar la mayor parte de la infanteria a España, concretamente a Cataluña, para intervenir en la ofensiva contra los franceses. Afortunadamente "cuando la Paz de Westfalia les privó de sus aliados holandeses y la Fronda empezó a preocuparles en el interior, Cataluña dejó de figurar destacadamente en los cálculos de Francia»" ${ }^{20}$.

Por fin, "cuatro docenas de navíos, dos de galeras y doscientos transportes, con catorce mil hombres de desembarco, efectivos impresio-

${ }^{16}$ Carta dirigida a don Juan José como Virrey de Sicilia. "...y considerando que no sera bastante la gente y provisiones que de esse Reyno podreis sacar con la Armada y que sera preciso que la mayor parte assi de infanteria como de cavalleria salga del Reyno de Napoles, junto con el caudal, muniçiones, bastimentos y dinero para su sustento! que esto se facilitara mucho, hallandose en la jornada el Conde de Oñate». (A.G.S., Secc. Estado, leg. 6112, fol. 48.)

17 Ibidem, fol. 24. Se trata de un despacho del Rey a don Juan con fecha 24 de marzo de 1649 .

18 lbidem, fol. 48.

${ }^{19}$ Ibidem, fol. 25.

${ }^{20}$ J. LYNCH: España bajo los Austrias, Barcelona, Península, 1975, 2. ${ }^{\circ}$ vol. p. 149. 
nantes que dan idea del alcance atribuido a la empresa, fueron puestos a las órdenes superiores de don Juan José de Austria” ${ }^{21}$. Atacados a un mismo tiempo Piombino y Puerto Longón, se rindieron en pocas semanas, en el verano de 1650. España recuperaba así, unas plazas de importante valor económico, político y estratégico.

Don Juan, a raíz de su intervención en Italia, se cubrió de gloria aunque se dice que fue el Conde de Oñate el que más contribuyó a sus éxitos militares.

Lo cierto es que a lo largo de su trayectoria, el Rey se preocupó de rodear a su hijo de expertos políticos y militares para que le ayudaran y aconsejaran en todo momento, lo cual, exasperaba a don Juan José cuya ambición le llevaba a desear ser cabeza visible de las empresas en las que participaba.

«Digame por amor de Dios..., qué lugar tengo yo en esta faccion (ejército), porque no veo otra ocupación sino de convoyar al Conde de Oñate, a quien hace S.M., dueño absoluto. Confieso a V.E., que ha sido este gran mortificación de mi aliento, y que mientras viva no se me borrara del corazón el concepto en que mi desdicha me ha puesto» ${ }^{22}$

Los informes que el Rey recibió sobre la conducta de don Juan José, el cual, había seducido a una de las hijas del pintor José Ribera, «El Españoleto", le animaron a enviarle hacia Cataluña, en junio de 1651. Al parecer, este hecho, no sólo no disgustó a don Juan, sino que era algo que esperaba desde hacía tiempo ${ }^{23}$.

${ }^{21} \mathrm{~J}$. Alcala-Zamora: “Razón de Estado y Geostrategia en la política italiana de Carlos II: Florencia y los Presidios" (1677-81), Boletín de la Real Academia de la Historia, t. CLXXIII. Cuaderno II, Madrid, 1976, p. 314.

22 Academia de la Historia. Carta de don Juan a don Luis de Haro (27 de julio de 1649), desde Mesina. Citada por A. Risco en obra citada anteriormente.

${ }^{23}$ En una carta enviada por don Luis de Haro a don Juan José con fecha 10 de junio de 1649, puede leerse: “Apruebo mucho la gran prudencia y acierto de VA, en suplicar a S.M. se sirva de no detener a V.A. en el govierno politico de Siçilia, sino permitir que se emplee su persona en ocassiones vibas de guerram (A.G.S., Secc. Estado, leg. 6112, fol. 56). 